BMJ Open

Diabetes

Research

\& Care

\title{
Medication regimen complexity and its impact on medication adherence and glycemic control among patients with type 2 diabetes mellitus in an Ethiopian general hospital
}

\author{
Asnakew Achaw Ayele, ${ }^{\oplus 1}$ Henok Getachew Tegegn, ${ }^{\oplus 1}$ Tadesse Awoke Ayele, ${ }^{2}$ \\ Mohammed Biset Ayalew ${ }^{1}$
}

To cite: Ayele AA, Tegegn HG, Ayele TA, et al. Medication regimen complexity and its impact on medication adherence and glycemic control among patients with type 2 diabetes mellitus in an Ethiopian general hospital. BMJ Open Diab Res Care 2019;7:e000685. doi:10.1136/ bmjdrc-2019-000685

Received 6 April 2019 Revised 20 May 2019 Accepted 30 May 2019

Check for updates

(C) Author(s) (or their employer(s)) 2019. Re-use permitted under CC BY-NC. No commercial re-use. See rights and permissions. Published by BMJ.

${ }^{1}$ Department of clinical pharmacy, School of Pharmacy, College of Medicineand Health Science, University of Gondar, Gondar, Ethiopia

${ }^{2}$ Department of Epidemiology and Biostatistics, Institute of Public health, College of Medicineand Health Science, University of Gondar, Gondar, Ethiopia

\section{Correspondence to} Mr Asnakew Achaw Ayele, Department of Clinical Pharmacy, School of Pharmacy, College of Medicineand Health Science, University of Gondar, Ethiopia, Gondar, Ethiopia; asnake.21.uog@gmail.com

\section{ABSTRACT}

Background Different studies reported that higher diabetes-specific Medication Regimen Complexity Index (MRCI) has a negative impact on glycemic control potentially by decreasing medication adherence. However, information about regimen complexity and its association with adherence and glycemic control in Ethiopian patients with diabetes is unknown.

Aim To evaluate medication regimen complexity and to assess its impact on medication adherence and glycemic control among patients with type 2 diabetes Mellitus (T2DM).

Methods A hospital-based cross-sectional design was conducted at Debre Tabor General Hospital from 1 May 2018 to 30 June 2018. Medication regimen complexity was evaluated using the 65 -item validated tool called Medication Complexity Index (MRCl). Adherence was measured using Morisky Medication Adherence Scale while patients were classified as having poor or good glycemic control based on the recent record of their fasting blood glucose. Multivariable logistic regression analysis was applied to determine the association between predictive variables and outcome variables.

Results A total of 275 patients with T2DM who meet the inclusion criteria were included in the final analysis. About $22.2 \%$ of the participants were classified as having high diabetes-specific MRCl, whereas $35.6 \%$ of the participants were classified as having high patient-level MRCI. The majority $(70.5 \%)$ of the respondents were adherent to their medications, and $42.9 \%$ of the total population were categorized as having good glycemic control. According to the result of the multivariate analysis, patients with low-level and moderate-level MRCl of both diabetes-specific and patient-level $\mathrm{MRCl}$ were more adherent to their medication compared with patients with high MRCl. High diabetes medication regimen complexity was associated with poor glycemic control in the adjusted analyses (adjusted $\mathrm{OR}=$ $0.276 ; 95 \% \mathrm{Cl}=0.10000 .759$ ).

Conclusion The prevalence of high MRCImedication regimen complexity index is high among patients with T2DM. Patients with low and moderate regimen complexity had improved adherence. High diabetes-specific medication regimen complexity was associated with poor glycemic control. Simplification of a complex medication

\section{Significance of this study}

What is already known about this subject?

D >Previous studies reported that higher diabetes-specific Medication Regimen Complexity Index (MRCl) has a negative impact on glycemic control potentially by decreasing medication adherence.

- However, little is known about medication regimen complexity and its effect on glycemic control and medication adherence among individuals with type 2 diabetes mellitus in resource-limiting settings.

What are the new findings?

- The prevalence of high medication regimen complexity was higher than previously reported findings.

- Individuals with low medication regimen complexity were found to be adherent to their medications.

- High diabetes-specific medication regimen complexity was negatively associated with good glycemic control.

How might these results change the focus of research or clinical practice?

- Patients with high MRCl should receive an extensive pharmaceutical care by clinical pharmacists to improve medication adherence and subsequent glycemic control.

- The findings of this research will alarm prescribers and pharmacist working in the hospital to focus on simplifying complex regimens whenever possible.

- Researchers should consider medication regimen complexity as a potential prediction model for non-adherence and poor glycemic control.

regimen for patients with diabetes should be sought by physicians and pharmacists to improve medication adherence and subsequent improvement in glycemic control.

\section{BACKGROUND}

International Diabetes Federation (IDF) reported that 425 million people had diabetes 
as of 2017 worldwide in which this figure up from an estimated 382 million people in 2013.1 2 The number is expected to be almost double by 2030.3 Diabetes mellitus (DM) is prevalent throughout the world but is more common (primarily type 2 ) in the more developed countries. However, there is a significant increase in prevalence in low-income and middle-income countries like Ethiopia where most patients will probably be found by 2030.3 The rise of its incidence in developing countries follows the trend of urbanization and lifestyle changes, including but not limited to increasingly sedentary lifestyles, physically inactive, marked by increased intake of foods that are high energy-dense but nutrient-poor. IDF estimated that 14.2 million are living with diabetes in Africa. $^{4}$

The proper use of antidiabetic medications over a sustained period and a recommended change of lifestyle are crucial for the success of glycemic control in the management of DM. ${ }^{5}$ Given the progressive nature of diabetes, many patients require complex medication regimens to achieve or maintain glycemic control. This is because most patients with DM are accompanied with other chronic comorbid conditions and yet, these chronic conditions required long-term use of medication which leads to a more complex medication regimen to such patients. Nearly $15 \%$ of patients require both insulin and oral antidiabetic medications to treat diabetes. ${ }^{6}$ Although complex medication regimens may aid some patients in achieving their glycemic control, such regimens may also decrease adherence and thus worsen glycemic control. ${ }^{7-9}$

Low adherence to prescribed antidiabetes medications accounts for $30 \%-50 \%$ of treatment failures, leading to worse treatment outcomes and which cause damages to vital organs. ${ }^{10}$ Besides, difficulties with medication therapy have a negative impact on the patients' perception of their health status and quality of life. ${ }^{11}$ With advances in medicine and longevity, the burden of medication regimens has increased. As of 2010, individuals using five or more prescription drugs increased by $70 \%$ as compared with the previous decade. ${ }^{12}$

Medication adherence could be influenced by many factors, including some individual factors (eg, socioeconomic status, age, sex, and race) and some health system factors (eg, health literacy, convenience of pharmacy, and medication regimen complexity). ${ }^{13-22}$ Medication regimen complexity is a modifiable factor that affects adherence and clinical outcomes. The collaboration of pharmacists and other healthcare professionals has been effective in simplification of complex regimens to improve adherence and clinical outcomes. ${ }^{23} 24$

A simple, universal measure of medication regimen complexity is a count of prescribed medications. However, medication count is unlikely to be an adequate measure of regimen complexity because it does not address other regimen characteristics contributing to complexity, such as dosage forms, dosing frequencies, and usage directions. Besides, medication count may not include over-the-counter (OTC) medications, which in some patients can contribute significantly to medication complexity. Higher treatment complexity is associated with lower rates of optimal adherence. ${ }^{25}$ Previous studies showed, for instance, higher adherence to a once-daily than a twice-daily regime ${ }^{2627}$ and a study using a composite score of drug administration, dosing frequency, and additional directions found that patients with low complexity scores were more often adherent than patients with high complexity scores. ${ }^{28}$ The result of a study which investigates the impact of Medication Regimen Complexity Index (MRCI) on glycemic control and medication adherence reported by Michael Pollack $e t$ $a l$ in 2010 revealed that treatment complexity has adverse effects on adherence and glycemic control. ${ }^{28}$ Moreover, the negative impacts of adherence on glycemic control have been established. ${ }^{29-31}$ There are a limited number of articles focusing on the evaluation of regimen complexity and its impact on adherence to antidiabetic treatment and glycemic control in developing countries like Ethiopia. A few studies in Ethiopia report that, being on an insulin drug regimen, consulting traditional healers, lack of financial resources, perceived side effects, experience depressive symptoms, and concerns about medications' safety were cited as the common factors for poor adherence among type $2 \mathrm{DM}$ (T2DM) ${ }^{32-34}$ A hospital-based cross-sectional study conducted at the University of Gondar Referral Hospital revealed that $64.7 \%$ of patients with DM had a poor level of glycemic control, as evidenced by $\mathrm{HbA1c}>7 \%$. Furthermore, this study reported that being on insulin treatment and poor medication adherence were found to be associated with poor glycemic control among patients with T2DM. ${ }^{35}$ Results of few studies revealed that patients with DM with complex medication regimen experience poor clinical outcomes and quality of life. ${ }^{1136}$ A cross-sectional survey conducted in Brazil by Samanta et al reported that patients with higher MRCI were associated with low scores in the physical, psychological, and overall quality of life domains. ${ }^{37}$ There are no data available regarding the impact of medication regimen complexity on medication adherence and glycemic control in Ethiopia so far. Therefore, the present study aimed at evaluating the complexity of medications and its impact on adherence and glycemic control among individuals with T2DM in Ethiopian general hospital.

\section{METHODS}

\section{Study design, study area, and period}

A hospital-based cross-sectional design was used for this study. The study was conducted at Debre Tabor General Hospital from 1 May 2018 to 30 June 2018. Debre Tabor General Hospital is found in Debre Tabor town, South Gondar Zone of Amhara Regional state which is 667 $\mathrm{km}$ far from Addis Ababa, the capital city of Ethiopia in Northwest direction and $102 \mathrm{~km}$ far from Bahir Dar town. It has both inpatient and outpatient departments. The outpatient department in this hospital cares for hypertensive, diabetes, asthmatic, and heart failure and other patients from the area. 


\section{Inclusion and exclusion criteria}

All patients with T2DM aged $>18$ years who visited the hospital for follow-up from 1 May 2018 to 30 June 2018 were included in the study. On the other hand, patients with incomplete chart record, those who were critically ill and unable to participate in the interview, and those who were recently diagnosed and had a follow-up of less than 6 months were excluded. The cut point 6 months was used by assuming that measuring and judging adherence and glycemic control in patients who are taking medications of less than 6 months is not feasible.

\section{Sample size determination and sampling technique}

The sample size was calculated using a single population proportion formula as follows

$$
n=\frac{z^{2} P(1-p)}{w^{2}}
$$

where $\mathrm{n}$ is the desired sample size for pollution of $>10$ $000, \mathrm{Z}$ is the standard normal distribution set as 1.96 (which corresponds to $95 \%$ CI), p value means that we used positive prevalence estimated to maximize the sample size, and $\mathrm{W}$ is the degree of accuracy 0.05 desired (a marginal error is 0.005):

Then the sample size is $\mathrm{n}=(1.96)^{2} 0.5((1-0.5) /$ $(0.05)^{2}=384$

Since the total population is $<10000$, that is about 750 ; we used the correction formula to determine the final sample size.

$$
\begin{gathered}
\frac{n}{1+(n / N)} \\
\frac{384}{1+384 / 750} \\
n f=274
\end{gathered}
$$

By adding $10 \%$ non-respondent, the final sample size is 278 .

\section{Data quality control measures}

Data collectors were trained intensively by the principal investigator (AAA) on the contents of the questionnaire, data collection methods, and ethical concerns. The filled questionnaire was checked daily for completeness by the principal investigator. The data collectors were two professional nurses working at Debre Tabor General Hospital chronic illness follow-up clinic.

\section{Data collection procedure and methods}

Clinical, demographic data, and patients' details of current medications were obtained from the chart. Socioeconomics, medication adherence status, and other demographics data that were not available from the chart were collected by interviewing the patients.

\section{Medication complexity}

MRCI is a validated 65-item tool for quantifying drug regimen complexity based on the quantity of medications, dosage form, dosage frequency, and additional instructions (eg, break/crush the tablet, take at a specified time, and relation to food/liquid). ${ }^{38}$. The instrument consists of three sections related to the route of drug administration (section A), dosing frequency (section $\mathrm{B}$ ), and additional directions (section $\mathrm{C}$ ). The sum of the scores of each of the three sections $(A+B+C)$ contributes to a complexity index. MRCI was calculated using the Microsoft Access V.1.0 medication regimen complexity electronic data capture tool. MRCI was analyzed in both diabetes specific and patient level. Medication regimen complexity was divided into three categories: low, moderate, and high. With the cut-off set at $\leq 4$ for low complexity, 5-8 for medium complexity, and a score $>8$ was considered as high complexity. The cut point was adapted from a previous study. ${ }^{40}$

\section{Medication adherence}

Medication adherence was measured using a recently validated Morisky Medication Adherence for Sub-Saharan counties. ${ }^{41}$

\section{Glycemic control}

Even tough hemoglobin A1c (HbA1c) is the gold standard, we have used fasting blood glucose (FBG) level to categorize patients as having poor or good glycemic control because of unavailability of HbA1C measurement service in the study area. The most recent FBG of each patient was taken from the medical record.

\section{Data entry and statistical analysis}

The data were cleaned and entered to analyze using IBM SPSS Statistics for Windows, V.20.0. Descriptive statistics like frequencies for categorical variables and means and SD for variables measured on a continuous scale were calculated. Association between predictive variables (regimen complexity, sociodemographic, and clinical data of patients) and dependent variables (adherence and glycemic control) using binary logistic regression was done. Therefore, univariate logistic regression, which is used to analyze the association between an individual independent variable and outcome of interest, was tested to compute the crude OR (COR), whereas multivariate logistic regression for analyzing two or more variables with the outcome of interest was also tested to compute the adjusted OR (AOR). Statistical significance was set at a two-sided $p$ value $<0.2$ for univariate and $<0.05$ in the multivariate analysis. Variables not significant at 0.2 were excluded from the final model.

\section{Ethical consideration}

Ethical approval was obtained from the institutional ethical review committee of the school of pharmacy, University of Gondar. Official Letter of cooperation was obtained from the medical director of Debre Tabor General Hospital. Informed verbal consent was also obtained from each respondent after explaining the purpose of the study. Participant's confidentiality was guaranteed by not recording their identifiers on the data collection formats. 
Operational definitions

Diabetes-specific MRCl

It was defined as the component of the MRCI that only included antidiabetic medications. ${ }^{40}$

\section{Patient-level MRCl}

It was defined as the overall MRCI, including antidiabetic medications in addition to all other prescription and OTC medications. ${ }^{40}$

\section{Medication adherence}

The extent to which a person's behavior taking antidiabetic medication corresponds with agreed recommendations from a healthcare provider. ${ }^{33}$

\section{Adherent}

Those patients who scored 8 from the 8-point response of the Morisky Medication Adherence Scale (MMAS). ${ }^{41}$

\section{Non-adherent}

Those patients who scored $<8$ from the 8-point response of MMAS- $8 .{ }^{41}$

\section{Good glycemic control}

Patients with FBG level between 70 and $130 \mathrm{mg} / \mathrm{dL}^{42}$

\section{Poor glycemic control}

Patients with FBG greater than 130 or less than $70 \mathrm{mg} /$ dL. ${ }^{42}$

\section{RESULTS}

Socio-demographics and clinical characteristics of the study participants

A total of 275 patients with T2DM who meet the inclusion criteria were included in the final analysis. Among the total of study participants, higher proportions of patients were women $(53.1 \%)$. The mean age of the study participants was 52.7 years with a SD of 9.94. A high percentage of the respondents, 128 (46.5), were unable to read and write. The mean $( \pm \mathrm{SD})$ duration since starting treatment of the patients was $6.08 \pm 4.37$ years ranging from 1 to 23 years, and $42.2 \%$ of the participants had at least one more disease in addition to T2DM. Details of other characteristics are available in table 1 .

\section{Regimen complexity, adherence, and glycemic control level}

Diabetes-specific MRCI ranged from 2 to 10; approximately one-third (31.3\%) was categorized as low complexity, $46.5 \%$ as moderate complexity, and $22.2 \%$ as high complexity. Patient-level MRCI ranged from 2 to 19; approximately $18.9 \%$ were categorized as low complexity, $45.5 \%$ as moderate complexity, and $35.6 \%$ as high complexity. Based on the Morisky adherence measuring tool, $194(70.5)$ of the respondents were adherent. Regarding the glycemic control level, the mean $( \pm \mathrm{SD})$ of FBG of the patients was $161.4 \pm 61.89$ ranging from 75 to $370 \mathrm{mg} / \mathrm{dL}$, and the majority of the study participants $157(57.1 \%)$ were categorized as having poor glycemic control (table 2).
Table 1 Socio-demographics and clinical characteristics of the participants $(\mathrm{N}=275)$

\begin{tabular}{|c|c|}
\hline $\mathrm{N}=\mathbf{2 7 5}$ & \\
\hline Total number of the study population, $\mathrm{N}$ & $\mathrm{N}(\%)$ \\
\hline \multicolumn{2}{|l|}{ Sex } \\
\hline Male & $129(46.9)$ \\
\hline Female & $146(53.1)$ \\
\hline Age, mean (SD) & $52.7 \pm 9.94$ \\
\hline \multicolumn{2}{|l|}{ Resident } \\
\hline Urban & $184(66.9)$ \\
\hline Rural & $91(33.1)$ \\
\hline \multicolumn{2}{|l|}{ Educational status } \\
\hline Unable to read and write & $128(46.5)$ \\
\hline Able to read and write & $52(18.9)$ \\
\hline Primary education & $15(5.5)$ \\
\hline Secondary school & $41(14.9)$ \\
\hline Higher education & $39(14.2)$ \\
\hline \multicolumn{2}{|l|}{ Employment status } \\
\hline Government employed & $61(22.2)$ \\
\hline Merchant & $43(15.6)$ \\
\hline Farmer & $75(27.3)$ \\
\hline Non-governmental organization employed & $20(7.3)$ \\
\hline Unemployed & $76(27.6)$ \\
\hline \multicolumn{2}{|l|}{ Monthly income in ETB } \\
\hline$<1500$ & $70(25.5)$ \\
\hline $1500-2500$ & $100(36.4)$ \\
\hline$\geq 2500$ & $105(38.2)$ \\
\hline \multicolumn{2}{|l|}{ Do you have insurance? } \\
\hline Yes & $93(33.8)$ \\
\hline No & $182(66.2)$ \\
\hline \multicolumn{2}{|l|}{ Ever had diabetic education } \\
\hline Yes & $220(80)$ \\
\hline No & $55(20)$ \\
\hline \multicolumn{2}{|l|}{ Distance from the Hospital } \\
\hline$<100 \mathrm{~km}$ & 207 (75.3) \\
\hline$>100 \mathrm{~km}$ & $68(24.7)$ \\
\hline $\begin{array}{l}\text { Duration since starting DM treatment, mean } \\
\text { (SD) }\end{array}$ & $6.08 \pm 4.37$ \\
\hline \multicolumn{2}{|l|}{ Comorbidity } \\
\hline Present & $116(42.2)$ \\
\hline Absent & $159(57.8)$ \\
\hline
\end{tabular}

DM, diabetes mellitus; ETB, Ethiopian Birr.

Association between regimen complexity and other variables with the level of adherence

According to the result of the multivariate analysis, a shift from high diabetes MRCI to moderate diabetes MRCI increases the likelihood of good antidiabetic medication adherence by 4.648 (AOR=4.648, 95\% CI: 2.097 to 10.300). Similarly, patients with low diabetes MRCI were six times more likely to be adherent with medications as compared 
Table 2 Percentage distribution of regimen complexity, adherence, and glycemic control level

\begin{tabular}{lr}
\hline Item & $\mathbf{N}(\%)$ \\
\hline $\begin{array}{l}\text { Diabetic-specific regimen complexity } \\
\text { Low }\end{array}$ & $86(31.3)$ \\
\hline Moderate & $128(46.5)$ \\
\hline High & $61(22.2)$ \\
\hline $\begin{array}{l}\text { Patient-level regimen complexity } \\
\text { Low total }\end{array}$ \\
\hline Moderate total & $52(18.9)$ \\
\hline High total & $125(45.5)$ \\
\hline Medication adherence & $98(35.6)$ \\
\hline Adherent & \\
\hline Non-adherent & $194(70.5)$ \\
Glycemic control & $81(29.5)$ \\
\hline Mean \pm SD & \\
\hline Good & $161.4 \pm 61.89$ \\
\hline Poor & $118(42.9)$ \\
\hline
\end{tabular}

with patients with high diabetes MRCI (AOR=6.569, 95\% CI: 2.628 to 16.420 ). The occurrence of good adherence to medications was four times more likely among patients with low patient-level MRCI (AOR=4.342, 95\% CI: 1.020 to 18.479) and three times among patients with medium patient-level MRCI compared with patients with high patient-level MRCI (AOR=3.351, 95\% CI: 1.351 to 8.115). Binary logistic regression of other variables indicated that patient having duration since starting treatment less than 10 years were two times more adherent than their counterparts (AOR=2.619, 95\% CI: 1.208 to 5.682). Besides, distance from the hospital $(<100 \mathrm{~km})$ had a statistically significant positive association with the likelihood of adherent to medications $(\mathrm{AOR}=2.039,95 \%$ CI: 0.801 to 5.187). However, patients with comorbidity had a $32 \%$ reduction in adherence level (AOR $=0.678,95 \%$ CI: 0.436 to 0.860 ). No other characteristics (age group, sex, residency, educational status, monthly income, employment status, etc) were significantly associated with the level of adherence (table 3 ).

\section{Association between regimen complexity and other variables with the level of glycemic control}

High diabetes medication regimen complexity was negatively associated with good glycemic control in the adjusted analyses (AOR $=0.276$; 95\% CI: 0.100 to 0.759 ). However, no significant difference in glycemic control was found with moderate diabetes-specific complexity regimens. Similarly, high and moderate patient-level regimen complexity index was not significantly associated with a difference in glycemic control level in both the unadjusted and adjusted analyses. The multivariate logistic regression of covariates revealed that being a farmer was inversely associated with good glycemic control compared with unemployed (AOR $=0.279$, 95\% CI: 0.098 to 0.797$)$. The level of adherence showed that non-adherent was negatively associated with good glycemic control (AOR=0.09, 95\% CI: 0.039 to 0.225 ). The presence of comorbidity is also another covariate that affects good glycemic control negatively $(\mathrm{AOR}=0.454,95 \% \mathrm{CI}$ : $0.231,0.890$ ) (table 4).

Patients with less than $100 \mathrm{~km}$ from the hospital were 13 times more likely to have good glycemic control compared with their counterparts (AOR $=13.195,95 \%$ CI: 3.193 to 54.517). Those who had been diagnosed with DM since more than 10 years were twice as likely to have poor glycemic control as those who had diabetes for less than 10 years.

\section{DISCUSSION}

Our study used a validated MRCI tool for quantifying the complexity of a medication regimen among patients with T2DM. To the best of our knowledge, this study was the first of its kind in Africa. We found that about $22 \%$ of the patients in this study had high diabetes MRCI, whereas $35 \%$ of patients had high patient-level MRCI according to a category of the measuring tool. This result was in line with findings from previously done research using MRCI as a complexity measuring tool. ${ }^{40}$ However, the findings of our regimen complexity level were lower than that of a study done using simple medication count as complexity measurement tool. ${ }^{43}$

Before the development of MRCI, regimen complexity was measured using a simple medication count in which it causes both overestimation and underestimation of the complexity level as many other components of the medication are ignored. ${ }^{40}$ For this study, medication regimen complexity was assessed using a validated measurement tool called MRCI, a 65-item instrument that can be calculated from data from patient's medical record. ${ }^{43}$ Complexity levels are based on a number of drugs, dosage frequency, additional instructions, and medication dosage forms. In the present study, the prevalence of high regimen complexity was higher in patient-level complexity compared with diabetes-specific complexity.

Because patient-level MRCI includes the diabetes-specific MRCI, one might debate that the complexity level of the overall regimen should reflect the complexity level of the antidiabetic regimen. However, the scoring could be influenced by the enormous collection of other prescriptions and OTC drugs which often overshadows the antidiabetic component. Thus, a high patient-level MRCI may not certainly arise from a high diabetes-specific MRCI.

Therefore, patient-level MRCI (including all prescription and OTC medications) is essential to evaluate, even when only addressing a specific disease treatment. Previous studies proved that patient-level MRCI scores were more than three times greater than disease-specific scores for each patient group. ${ }^{44}$ Ended, our research highlights the need for complete information about all types of patient medications while evaluating medication regimen complexity. 


\begin{tabular}{|c|c|c|c|c|c|}
\hline \multirow[t]{2}{*}{ Variables } & \multicolumn{2}{|l|}{ Level of adherence } & \multicolumn{3}{|l|}{ OR $(95 \%, \mathrm{Cl})$} \\
\hline & Non-adherent (n) & Adherent (n) & COR & AOR & $P$ value \\
\hline \multicolumn{6}{|l|}{$\begin{array}{l}\text { Diabetes-specific } \\
\text { MRCI }\end{array}$} \\
\hline Low diabetes MRCI & 14 & 72 & 7.40 (3.44 to 15.94$)$ & 6.569 (2.628 to 16.420$)$ & $<0.001$ \\
\hline $\begin{array}{l}\text { Moderate diabetes } \\
\mathrm{MRCl}\end{array}$ & 31 & 97 & 4.50 (2.35 to 8.64$)$ & 4.648 (2.097 to 10.300$)$ & $<0.001$ \\
\hline High diabetes MRCI & 36 & 25 & 1 & 1 & - \\
\hline \multicolumn{6}{|l|}{ Patient-level MRCI } \\
\hline Low total MRCI & 7 & 45 & 6.42 (2.64 to 15.64$)$ & 4.342 (1.020 to 18.479$)$ & 0.047 \\
\hline Moderate total MRCI & 25 & 100 & 4.00 (2.21 to 7.22$)$ & 3.351 (1.351 to 8.115$)$ & 0.009 \\
\hline High total $\mathrm{MRCl}$ & 49 & 49 & 1 & 1 & - \\
\hline \multicolumn{6}{|l|}{ Other variables } \\
\hline \multicolumn{6}{|l|}{ Sex } \\
\hline Male & 43 & 86 & 1 & & \\
\hline Female & 38 & 108 & 0.704 (0.418 to 1.184$)$ & & \\
\hline \multicolumn{6}{|l|}{ Age (years) } \\
\hline$<64$ & 72 & 167 & 1 & & \\
\hline$\geq 64$ & 9 & 27 & 0.773 (0.346 to 1.727$)$ & & \\
\hline \multicolumn{6}{|l|}{ Residency } \\
\hline Urban & 53 & 131 & 1 & & \\
\hline Rural & 28 & 63 & 1.099 (0.635 to 1.900$)$ & & \\
\hline \multicolumn{6}{|l|}{ Educational status } \\
\hline $\begin{array}{l}\text { Unable to read and } \\
\text { write }\end{array}$ & 41 & 87 & 0.172 (0.047 to 0.628$)$ & 0.856 (0.168 to 4.362$)$ & 0.494 \\
\hline $\begin{array}{l}\text { Able to read and } \\
\text { write }\end{array}$ & 14 & 39 & 0.936 (0.364 to 2.407$)$ & 1.046 (0.341 to 3.213$)$ & 0.934 \\
\hline Primary education & 10 & 5 & 0.72 (0.326 to 1.643$)$ & 1.874 (0.637 to 5.518$)$ & 0.254 \\
\hline $\begin{array}{l}\text { Secondary } \\
\text { education }\end{array}$ & 6 & 35 & 2.011 (0.653 to 6.199$)$ & 2.632 (0.731 to 9.497$)$ & 0.139 \\
\hline Higher education & 10 & 29 & 1 & 1 & - \\
\hline \multicolumn{6}{|l|}{ Employment status } \\
\hline $\begin{array}{l}\text { Government } \\
\text { employed }\end{array}$ & 12 & 49 & 1.885 (0.851 to 4.174$)$ & & \\
\hline Merchant & 12 & 31 & $1192(0.523$ to 2.716$)$ & & \\
\hline Farmer & 28 & 47 & 0.775 (0.395 to 1.518$)$ & & \\
\hline $\begin{array}{l}\text { Non-governmental } \\
\text { organization } \\
\text { employed }\end{array}$ & 5 & 15 & 1.385 (0.451 to 4.251$)$ & & \\
\hline Unemployed & 24 & 52 & 1 & & \\
\hline \multicolumn{6}{|l|}{ Monthly income in ETB } \\
\hline$<1500$ & 13 & 57 & 1.754 (0.840 to 3.662$)$ & 1.924 (0.737 to 5.022$)$ & 0.181 \\
\hline $1500-2500$ & 38 & 62 & 0.653 (0.364 to 1.172$)$ & 0.790 (0.348 to 1.798$)$ & 0.574 \\
\hline$\geq 2500$ & 30 & 75 & 1 & 1 & - \\
\hline \multicolumn{6}{|l|}{$\begin{array}{l}\text { Do you have } \\
\text { insurance? }\end{array}$} \\
\hline Yes & 31 & 62 & 1 & 1 & - \\
\hline No & 50 & 132 & 0.758 (0.441 to 1.300$)$ & 0.592 (0.232 to 1.512$)$ & 0.74 \\
\hline
\end{tabular}

Continued 
Table 3 Continued

\begin{tabular}{|c|c|c|c|c|c|}
\hline \multirow[t]{2}{*}{ Variables } & \multicolumn{2}{|l|}{ Level of adherence } & \multicolumn{3}{|l|}{ OR $(95 \%, \mathrm{Cl})$} \\
\hline & Non-adherent (n) & Adherent (n) & COR & AOR & $P$ value \\
\hline \multicolumn{6}{|c|}{$\begin{array}{l}\text { Ever had diabetic } \\
\text { education }\end{array}$} \\
\hline Yes & 69 & 151 & 1 & 1 & - \\
\hline No & 12 & 43 & 0.611 (0.303 to 1.230$)$ & $0.540(0.231$ to 1.263$)$ & 0.155 \\
\hline \multicolumn{6}{|c|}{$\begin{array}{l}\text { Distance from the } \\
\text { hospital }\end{array}$} \\
\hline$<100$ km & 54 & 153 & 1.866 (1.048 to 3.320$)$ & 2.039 (0.801 to 5.187$)$ & 0.013 \\
\hline$>100 \mathrm{~km}$ & 27 & 41 & 1 & 1 & - \\
\hline \multicolumn{6}{|c|}{$\begin{array}{l}\text { Duration since starting } \\
\text { DM treatment }\end{array}$} \\
\hline$<10$ years & 57 & 168 & 2.721 (1.448 to 5.113$)$ & 2.619 (1.208 to 5.682$)$ & 0.015 \\
\hline$\geq 10$ years & 24 & 26 & 1 & 1 & \\
\hline \multicolumn{6}{|l|}{ Comorbidity } \\
\hline Present & 44 & 72 & 0.496 (0.293 to 0.839$)$ & 0.678 (0.436 to 0.860$)$ & 0.012 \\
\hline Absent & 37 & 122 & 1 & 1 & - \\
\hline
\end{tabular}

Bold indicates p-value of less than 0.05

AOR, adjusted OR; COR, crude OR; ETB, Ethiopian Birr; MRCI, Medication Regimen Complexity Index.

This study found that $70.5 \%$ of the study population had good adherence to their antidiabetic medications, evidenced in an MMAS-8 score of 8. The result is comparable to other studies in Ethiopia using the MMAS-8 with similar cut-off points. ${ }^{34} 354546$

Complex medication regimens may contribute to non-adherence more than the overall number of drugs taken. Logically, therapeutic regimen factors, such as daily frequency, dosage forms, and additional instructions (eg, the necessity to cut or crush tablets) could significantly impact medication adherence, particularly in patients with diabetes. Surprisingly, only a few studies considered regimen complexity factors as potential factors of adherence level in patients with diabetes globally ${ }^{40}$ and Ethiopia $^{3445}$

In our study, good correlation was found between low and moderate diabetes MRCI and adherence. After controlling for patient characteristics, patients who were on low diabetes-specific MRCI were six times more likely to be adherent when compared with high complexity. A similar level of adherence improvement was observed in patients with a low level of patient-level MRCI. Although the factors responsible for adherence to medication in diabetes treatment are variable, in addition to regimen complexity, this study revealed that distance from the hospital, duration since starting treatment, and the presence of co-morbidity were statistically associated with the level of adherence.

Our study found that the proportion of patients with good glycemic control is $42.9 \%$. This finding is higher than the study done at Gondar University Hospital, Ethiopia. ${ }^{35}$ The discrepancy between the findings of this study and done elsewhere could be clarified by the fact that previous studies used the recommended test for glycemic control (HbA1c test), whereas our study used the FBG test for category of glycemic control level. This study explored the relationship between MRCI and glycemic control level. The ADA (American Diabetes Association) standards of medical care guide treatment of T2DM, which focus on a patient-centered approach. The standards do not give preference to any particular drug or drug class after metformin monotherapy, instead offering three options: a second oral agent or basal insulin. Patient-specific considerations mentioned in the guidelines include efficacy, cost, potential adverse effects, weight, comorbidities, hypoglycemia risk, and patient preferences. ${ }^{42}$ Recently, the ADA standards added an increased emphasis on adherence, which "should be addressed as the priority" when treatment goals are not met. Medication factors, including regimen complexity and medication adherence, are acknowledged as potential barriers to glycemic control. ${ }^{42}$

After adjusting for confounding factors, patients with high complexity treatment regimens were $72 \%$ less likely to be having good glycemic control than patients with low diabetes-specific regimen complexity $(\mathrm{AOR}=0.276$; 95\% CI: 0.100 to 0.759 ). The association between increased diabetes-specific regimen complexity and poor glycemic control indicates that treatment complexity can add to disease burden in patients with diabetes without improving glycemic control. This finding is supported by previous evidence that high diabetes-specific MRCI of antidiabetic was correlated with poorer glycemic control, possibly linked to diminished adherence. ${ }^{28}$ However, in our study, significant association was not observed between patient-level MRCI and glycemic control. The lack of significant correlations between patient-level medication 
Table 4 Test of association between predictive variables with glycemic control

\begin{tabular}{|c|c|c|c|c|c|}
\hline \multirow[b]{2}{*}{ Variables } & \multicolumn{2}{|c|}{$\begin{array}{l}\text { Glycemic control } \\
\text { level }\end{array}$} & \multicolumn{2}{|l|}{ OR, 95\% Cl } & \multirow[b]{2}{*}{$P$ value } \\
\hline & Poor & Good & COR & AOR & \\
\hline \multicolumn{6}{|l|}{ Diabetes-specific MRCI } \\
\hline Low diabetes $\mathrm{MRCl}$ & 34 & 52 & 1 & 1 & - \\
\hline Moderate diabetes $\mathrm{MRCl}$ & 83 & 45 & 2.583 (1.313 to 5.083$)$ & 0.922 (0.294 to 2.896$)$ & 0.890 \\
\hline High diabetes $\mathrm{MRCl}$ & 40 & 21 & 1.029 (0.546 to 1.940$)$ & 0.276 (0.100 to 0.759$)$ & 0.013 \\
\hline \multicolumn{6}{|l|}{ Patient-level MRCI } \\
\hline Low total $\mathrm{MRCl}$ & 18 & 34 & 1 & 1 & - \\
\hline Moderate total $\mathrm{MRCl}$ & 70 & 55 & 3.754 (1.851 to 7.612$)$ & 1.078 (0.314 to 3.696$)$ & 0.905 \\
\hline High total $\mathrm{MRCl}$ & 69 & 29 & 1.754 (1.009 to 3.049$)$ & 1.239 (0.523 to 2.934$)$ & 0.626 \\
\hline \multicolumn{6}{|l|}{ Adherence level } \\
\hline Adherent & & & 1 & 1 & - \\
\hline Non-adherent & & & 0.173 (0.091 to 0.330$)$ & 0.09 (0.039 to 0.225$)$ & $<0.001$ \\
\hline \multicolumn{6}{|l|}{ Other variables } \\
\hline \multicolumn{6}{|l|}{ Sex } \\
\hline Male & 83 & 46 & 1 & & \\
\hline Female & 74 & 72 & 0.609 (0.376 to 0.987$)$ & & \\
\hline \multicolumn{6}{|l|}{ Age (years) } \\
\hline$<64$ & 133 & 106 & 1.649 (0.788 to 3.450$)$ & 1.364 (0.587 to 3.168 ) & 0.471 \\
\hline$\geq 64$ & 24 & 12 & 1 & 1 & - \\
\hline \multicolumn{6}{|l|}{ Resident } \\
\hline Urban & 99 & 85 & 1 & 1 & \\
\hline Rural & 58 & 33 & 1.471 (0.880 to 2.460$)$ & 1.403 (0.442 to 4.454$)$ & 0.651 \\
\hline \multicolumn{6}{|l|}{ Educational status } \\
\hline Unable to read and write & 75 & 53 & 0.879 (0.428 to 1.806$)$ & & \\
\hline Able to read and write & 25 & 27 & $1.361(0.592$ to 3.1130$)$ & & \\
\hline Primary education & 9 & 6 & $0.583(0.168$ to 2.025$)$ & & \\
\hline Secondary education & 27 & 14 & $0.605(0.246$ to 1.490$)$ & & \\
\hline Higher education & 21 & 18 & 1 & & \\
\hline \multicolumn{6}{|l|}{ Employment status } \\
\hline Government employed & 36 & 25 & 1 & 1 & - \\
\hline Merchant & 32 & 11 & 0.264 (0.116 to 0.600$)$ & 0.322 (0.102 to 1.017$)$ & 0.053 \\
\hline Farmer & 48 & 27 & $0.432(0.224$ to 0.830$)$ & 0.279 (0.098 to 0.797$)$ & 0.017 \\
\hline $\begin{array}{l}\text { Non-governmental } \\
\text { organization employed }\end{array}$ & 8 & 12 & 1.151 (0.422 to 3.139$)$ & 4.059 (0.775 to 21.253$)$ & 0.097 \\
\hline Unemployed & 33 & 43 & 0.533 (0.69 to 1.055$)$ & 1.268 (0.354 to 4.549$)$ & 0.715 \\
\hline \multicolumn{6}{|l|}{ Monthly income in ETB } \\
\hline$<1500$ & 33 & 37 & 1 & 1 & - \\
\hline $1500-2500$ & 57 & 43 & 1.977 (1.068 to 3.658$)$ & 0.755 (0.271 to 2.102$)$ & 0.59 \\
\hline$\geq 2500$ & 67 & 38 & 1.330 (0.759 to 2.332$)$ & 1.724 (0.719 to 4.131$)$ & 0.222 \\
\hline \multicolumn{6}{|l|}{ Do you have insurance? } \\
\hline Yes & 54 & 39 & 1 & & \\
\hline No & 103 & 79 & 0.962 (0.581 to 1.593$)$ & & \\
\hline \multicolumn{6}{|l|}{ Ever had diabetic education } \\
\hline Yes & 124 & 96 & 1.097 (0.603 to 1.996$)$ & 1.27 (0.594 to 2.736$)$ & 0.533 \\
\hline
\end{tabular}

Continued 
Table 4 Continued

\begin{tabular}{|c|c|c|c|c|c|}
\hline \multirow[b]{2}{*}{ Variables } & \multicolumn{2}{|c|}{$\begin{array}{l}\text { Glycemic control } \\
\text { level }\end{array}$} & \multicolumn{2}{|l|}{ OR, 95\% Cl } & \multirow[b]{2}{*}{$P$ value } \\
\hline & Poor & Good & COR & AOR & \\
\hline No & 33 & 22 & 1 & & \\
\hline \multicolumn{6}{|c|}{ Distance from the hospital } \\
\hline$<100 \mathrm{~km}$ & 106 & 101 & 2.698 (1.475 to 4.935$)$ & 13.195 (3.193 to 54.517$)$ & $<0.001$ \\
\hline$>100 \mathrm{~km}$ & 51 & 17 & 1 & 1 & - \\
\hline \multicolumn{6}{|c|}{$\begin{array}{l}\text { Duration since starting DM } \\
\text { treatment }\end{array}$} \\
\hline$<10$ years & 125 & 100 & 1 & 1 & - \\
\hline$\geq 10$ years & 32 & 18 & $0.678(0.360$ to 1.279$)$ & $0.736(0.345$ to 1.568$)$ & 0.427 \\
\hline \multicolumn{6}{|l|}{ Comorbidity } \\
\hline Present & 77 & 39 & $0.520(0.317$ to 0.851$)$ & $0.454(0.231$ to 0.890$)$ & 0.010 \\
\hline Absent & 80 & 79 & 1 & 1 & - \\
\hline
\end{tabular}

Bold indicates $p$-value of less than 0.05

1, Reference; AOR, adjusted OR; COR, crude OR; ETB, Ethiopian Birr; MRCI, Medication Regimen Complexity Index.

regimen complexity and glycemic control does not mean that complexity is not an important issue in managing glycemic controls. It is important to bear in mind that non-antidiabetic medications that are commonly used in this population such as antihypertensive medications, lipid-lowering therapy, and aspirin could be the reason. Even though these medications increase the patient-level MRCI, some of these medications may be associated with secondary effects on the glucose level.

This study also highlighted the strong association between medication adherence and glycemic status after adjustment for confounding factors including regimen complexity. Patients with non-adherent to their antidiabetic medication had poor glycemic level compared with those who adhered to their medications. Other studies had similar findings ${ }^{35} 47$; educational status, distance from the hospital, and the presence of comorbidity were other variables associated with glycemic control.

\section{STRENGTHS AND LIMITATIONS OF THE STUDY}

The number of medications per day, the type of dosage form, dose frequency, and additional instructions are essential components of medication regimen complexity but do not adequately address in the previous studies. Moreover, regimen complexity was not considered as a potential challenge in both adherence and glycemic control. This is the first reported research in Africa that evaluates regimen complexity and its association with adherence and glycemic control using a validated tool. However, our research has two main limitations. First, the MRCI was calculated using only what was captured in the medical chart order shit. As a result, any medications or instructions not recorded were missed. Second, we have used FBG to categorize the patient as having good and poor glycemic control.

\section{CONCLUSIONS}

High medication regimen complexity is typical among patients with T2DM. The prevalence of high patient-level MRCI was higher than that of diabetes-specific MRCI. Low and medium medication regimen complexity was associated with the right adherence level. Distance from the hospital, duration since starting treatment, and the presence of comorbidity were statistically significant factors affecting medication adherence. High diabetes-specific MRCI was associated with poor glycemic control. Educational status, distance from the hospital, and the presence of comorbidity were other co-varieties associated with glycemic control. ${ }^{47} 48$

Contributors AAA involved in the conception, study tool development, data analysis, and final write-up and editing and approval of the final manuscript. HGT involved supervision and revising the final manuscript, MBA and TAA involved in principal supervision and approval of the final manuscript.

Funding The authors have not declared a specific grant for this research from any funding agency in the public, commercial or not-for-profit sectors.

Competing interests No, there are no competing interests for any author.

Provenance and peer review Not commissioned; externally peer reviewed.

Data availability statement Data are available upon reasonable request. All data relevant to the study are included in the article or uploaded as supplementary information.

Open access This is an open access article distributed in accordance with the Creative Commons Attribution Non Commercial (CC BY-NC 4.0) license, which permits others to distribute, remix, adapt, build upon this work non-commercially, and license their derivative works on different terms, provided the original work is properly cited, appropriate credit is given, any changes made indicated, and the use is non-commercial. See: http://creativecommons.org/licenses/by-nc/4.0/.

\section{REFERENCES}

1. International Diabetes Federation. IDF Diabetes Atlas. 8th edn. Brussels, Belgium: International Diabetes Federation, 2017.

2. Shi Y, Hu FB. The global implications of diabetes and cancer. The Lancet 2014;383:1947-8. 
3. Wild S, Roglic G, Green A, et al. Global prevalence of diabetes: estimates for the year 2000 and projections for 2030. Diabetes Care 2004;27:1047-53.

4. Federation, International Diabetes. IDF diabetes atlas. (seventh ed.). Brussels: international diabetes Federation. ISBN 9782930229812. OCLC 961366911, 2015. Available: https://www.worldcat.org/oclc/ 961366911

5. Al-Qazaz HK, Hassali MA, Shafie AA, et al. The eight-item Morisky Medication Adherence Scale MMAS: translation and validation of the Malaysian version. Diabetes Res Clin Pract 2010;90:216-21.

6. Centers for disease control and prevention. National diabetes statistics report: estimates of diabetes and its burden in the United States. Atlanta, GA: US department of health and Human services, 2014.

7. Hessler D, Fisher L, Glasgow RE, et al. Reductions in regimen distress are associated with improved management and glycemic control over time. Diabetes Care 2014;37:617-24.

8. Donnelly LA, Morris AD, Evans JMM, et al. Adherence to insulin and its association with glycaemic control in patients with type 2 diabetes. QJM 2007;100:345-50.

9. Dailey G, Kim MS, Lian JF. Patient compliance and persistence with anti-hyperglycemic therapy: evaluation of a population of type 2 diabetic patients. J Int Med Res 2002;30:71-9.

10. ARftACoP M. Medication adherence time tool: improving health outcomes. in: medication adherence clinical reference. American College of Preventive Medicine, Washington, DC, $p$ 2011;202:466-2044.

11. Okano GJ, Malone DC, Billups SJ, et al. Reduced quality of life in veterans at risk for drug-related problems. Pharmacotherapy 2001;21:1123-9.

12. Gu Q, Dillion CF, Burt VL. Prescription drug use continues to increase. NCHS Data Brief 2010;42:1-8.

13. Maddigan SL, Farris KB, Keating N, et al. Predictors of Older Adults Capacity for Medication Management in a Self-Medication Program. $J$ Aging Health 2003;15:332-52.

14. Stephenson J. Noncompliance may cause half of antihypertensive drug 'failures.' . JAMA 1999;282:313-4.

15. Sabate E. Adherence to long-term therapies: evidence for action who report. Contract No: Document Number, 2003.

16. Sokol MC, McGuigan KA, Verbrugge RR, et al. Impact of medication adherence on hospitalization risk and healthcare cost. Med Care 2005;43:521-30.

17. Vlasnik JJ, Aliotta SL, DeLor B. Medication adherence: factors influencing compliance with prescribed medication plans. Case Manager 2005;16:47-51.

18. Bezie Y, Molina M, Hernandez N, et al. Therapeutic compliance: a prospective analysis of various factors involved in the adherence rate in type 2 diabetes. Diabetes \& Metabolism 2006;32:611-6.

19. Dragomir A, Côté R, Roy L, et al. Impact of adherence to antihypertensive agents on clinical outcomes and hospitalization costs. Medical Care 2010;48:418-25.

20. Krousel-Wood M, Islam T, Muntner P, et al. Association of depression with antihypertensive medication adherence in older adults: crosssectional and longitudinal findings from CoSMO. ann. behav. med. 2010;40:248-57

21. May HT, Sheng X, Catinella AP, et al. Antilipidemic adherence postcoronary artery disease diagnosis among those with and without an ICD-9 diagnosis of depression. Journal of Psychosomatic Research 2010;69:169-74.

22. Mazzaglia G, Ambrosioni E, Alacqua M, et al. Adherence to antihypertensive medications and cardiovascular morbidity among newly diagnosed hypertensive patients. Circulation 2009;120:1598-605.

23. McLean DL, McAlister FA, Johnson JA, et al. A randomized trial of the effect of community pharmacist and nurse care on improving blood pressure management in patients with diabetes mellitus: a study of cardiovascular risk intervention by pharmacistshypertension (SCRIP-HTN). Arch Intern Med 2008;168:2355-61.

24. Carter BL, Bergus GR, Dawson JD, et al. A cluster randomized trial to evaluate Physician/Pharmacist collaboration to improve blood pressure control. J Clin Hypertension 2008;10:260-71.

25. Ingersoll KS, Cohen J. The impact of medication regimen factors on adherence to chronic treatment: a review of literature. J Behav Med 2008;31:213-24.

26. Malmenäs M, Bouchard JR, Langer J. Retrospective real-world adherence in patients with type 2 diabetes initiating oncedaily liraglutide $1.8 \mathrm{Mg}$ or twice-daily exenatide $10 \mu \mathrm{g}$. Clinical Therapeutics 2013;35:795-807.
27. Dezii CM, Kawabata H, Tran M. Effects of once-daily and twice-daily dosing on adherence with prescribed glipizide oral therapy for type 2 diabetes. Southern Medical Journal 2002;95:68-71.

28. Pollack M, Chastek B, Williams SA, et al. Impact of treatment complexity on adherence and glycemic control: an analysis of oral antidiabetic agents. 2010;17:257-65

29. Fabunmi R, Nielsen LL, Quimbo R, et al. Patient characteristics, drug adherence patterns, and hypoglycemia costs for patients with type 2 diabetes mellitus newly initiated on exenatide or insulin glargine. Current Medical Research and Opinion 2009;25:777-86.

30. Lawerence DB, Ragucci KR, Long LB, et al. Relationship of oral antihyperglycemic (sulfonylurea or metformin) medication adherence and hemoglobin A1c goal attainment for HMO patients enrolled in a diabetes disease management program. JMCP 2006;12:466-71.

31. Rozenfeld Y, Hunt JS, Plauschinat $C$, et al. Oral antidiabetic medication adherence and glycemic control in managed care. Am J Manag Care 2008;14:71-5.

32. Abebe SM, Berhane Y, Worku A. Barriers to diabetes medication adherence in North West Ethiopia. SpringerPlus 2014;3.

33. Wabe NT, Angamo MT, Hussein S. Medication adherence in diabetes mellitus and self-management practices among people with type-2 diabetes in Ethiopia. North American journal of medical sciences 2011;3.

34. Teklay G, Hussien J, Tesfaye D. Non-adherence and associated factors among type 2 diabetic patients at Jimma university specialized Hospital, Southwest Ethiopia. J. of Medical Sciences 2013;13:578-84.

35. Abebe SM, Berhane yemane, Worku A, et al. Level of sustained glycemic control and associated factors among patients with diabetes mellitus in Ethiopia: a hospital-based cross-sectional study. Diabetes, Metabolic Syndrome and Obesity: Targets and Therapy 2015;8.

36. ManasseHRJr. Medication use in an imperfect world: drug misadventuring as an issue of public policy, part 1. am J Hosp pharm 1989;46:929-44.

37. Fröhlich SE, Zaccolo AV, da Silva SLC, et al. Association between drug prescribing and quality of life in primary care. Pharm World Sci 2010;32:744-51.

38. Hirsch JD, Metz KR, Hosokawa PW, et al. Validation of a patientlevel medication regimen complexity index as a possible tool to identify patients for medication therapy management intervention. Pharmacotherapy: The Journal of Human Pharmacology and Drug Therapy 2014;34:826-35.

39. George J, Phun Y-T, Bailey MJ, et al. Development and validation of the medication regimen complexity index. Ann Pharmacother 2004;38:1369-76.

40. Yeh A, Shah-Manek B, Lor KB. Medication regimen complexity and A1c goal attainment in underserved adults with type 2 diabetes. Ann Pharmacother 2017;51:111-7.

41. Tandon S, Chew M, Eklu-Gadegbeku CK, et al. Validation and psychometric properties of the 8-item Morisky Medication Adherence Scale (MMAS-8) in type 2 diabetes patients in subSaharan Africa. Diabetes Res Clin Pract 2015;110:129-36.

42. American Diabetes Association. Standards of Medical Care in Diabetes-2017 Abridged for Primary Care Providers. Clin Diabetes 2017;35:5-26.

43. Viktil KK, Blix HS, Moger TA, et al. Polypharmacy as commonly defined is an indicator of limited value in the assessment of drugrelated problems. Br J Clin Pharmacol 2007;63:187-95.

44. Rettig SM, Wood Y, Hirsch JD. Medication regimen complexity in patients with uncontrolled hypertension and/or diabetes. Journal of the American Pharmacists Association 2013;53:427-31.

45. Gelaw BK, Mohammed A, Tegegne GT, et al. Nonadherence and contributing factors among ambulatory patients with antidiabetic medications in Adama referral hospital. J Diabetes Res 2014;2014:1-9.

46. Tewabe T, Kindie S. Level of insulin adherence among diabetes mellitus patients in Felege Hiwot referral hospital, Bahir Dar, Northwest Ethiopia, 2017: a cross-sectional study. BMC Res Notes 2018;11.

47. Radwan M, Elsous $\mathrm{A}, \mathrm{Al}-\mathrm{Sharif} \mathrm{H}$, et al. Glycemic control among primary care patients with type 2 diabetes mellitus in the Gaza Strip, Palestine. Ther Adv Endocrinol Metab 2018;9:3-14.

48. Pascal IG, Ofoedu JN, Uchenna NP, et al. Blood glucose control and medication adherence among adult type 2 diabetic Nigerians attending a primary care clinic in under-resourced environment of Eastern Nigeria. N Am J Med Sci 2012;4. 